Original Article

\title{
Study on Early Childhood Adversities of Orphans Rearing in Orphanages
}

\author{
${ }^{*}$ Mahmood $\mathrm{F}^{1}$, Khan $\mathrm{NR}^{2}$, Islam $\mathrm{MZ}^{3}$, Shahreen $\mathrm{T}^{4}$, Zaman $\mathrm{NA}^{5}$
}

\begin{abstract}
Orphans spread a significant mass of our absolute child folks and this study was planned to determine the early childhood adversities of orphans that may attract them in various violence and perilous fortune lead further that in the end have a long-standing psycho-social impact on their adulthood. This was a cross-sectional study that was completed among 301orphans of both genders. The subjects were chosen by convenient sampling technique based on specific inclusion criteria and maintaining ethical issues. The study was directed from January to December 2017 in different orphanages of Chittagong and Dhaka city. The examination uncovered, maximum (84\%) of participants were male and the rest (16\%) were female. Among them, around 44.9\% of them were matured from 10-12 years followed by 37.9\% matured between 13-15 years. The majority (62\%) of the participants had education up to primary/equivalent level. A maximum (69.77\%) of them lost their father and $17.94 \%$ of them lost both of their parentages. The study revealed, physical assault (30.2\%), serious domestic accident (27\%), and life-threatening illness/injury (33.6\%) had higher frequencies than other events that happened with the participants personally. Additionally, events like traffic transportation accidents (47.3\%), serious domestic accidents (36.8\%), and physical assault (28.3\%) had higher frequencies than other events experienced through observing to transpiring. Then again, transportation accidents, domestic accidents $\left(\chi^{2}\right.$
\end{abstract}

1. *Dr. Fahad Mahmood, Lecturer, Department of Community Medicine, National Institute of Preventive and Social Medicine (NIPSOM), Dhaka. Email: fahadmahmud999@gmail.com

2. Dr. Nirmeen Rifat Khan (Rtd.), Professor, Department of Community Medicine, NIPSOM, Dhaka.

3. Dr. Md. Ziaul Islam PhD, Professor and Head of the Department of Community Medicine, NIPSOM, Dhaka.

4. Dr. Tasmia Shahreen, Medical Officer, Lab Call Centre, DGHS, Dhaka

5. Dr. Md. Noor Ashad-Uz-Zaman, Lecturer, Department of Public Health \& Hospital Administration, NIPSOM, Dhaka.

${ }^{*}$ For Correspondence
$=32.673, \quad$ p 0.05), physical assault, life-threatening illness/injury were experienced among 16-18 years of aged orphans personally where assault with a weapon and sexual assault ( $\left.\chi^{2}=14.637, p<0.05\right)$ were more frequent among 13-15 years old gathering.

Keyword: Orphan, childhood adversity

\section{INTRODUCTION}

UNICEF and global partners outlined an orphan as a child under 18 years of age who has lost one or both parents to any cause of death. According to this outlining, there were nearly 140 million orphans worldwide in 2015, including 61 million in Asia, 52 million in Africa, 10 million in Latin America and the Caribbean and 7.3 million in Eastern Europe and Central Asia.

This outsized number speaks to youngsters who have lost the two guardians as well as the individuals who have lost their dad however have an enduring mother or have lost their mother yet have an enduring father. Of this around 140 million kids delegated orphans, among them about 15.1 million have lost the two guardians. Proof obviously shows that by far most of orphans are living with an enduring guardian grandparent or with other relative for endurance. ${ }^{1}$

According to UNICEF, about 95 per cent of all orphans globally are over five years of age. ${ }^{1}$ Some of them are lucky enough of getting possibility of being raised up in orphanages having convenience and instructive offices and the rest spend their adolescence in streets, railroad stations, and ghettos in a random way. These vulnerable children including orphans are especially defenseless as they often experience physical abuse from their employers. Moreover, the number of orphans and children living on streets is increasing. Orphans in our country are struggling to survive in harsh conditions surrounded by everyday violence. $^{2}$

At the point when guardians bite the dust, kids miss their physical presence, yet additionally miss the numerous positive things they gave them when they were alive, for example, love, care and insurance. By and large, orphans and weak kids have nobody to share their hopelessness. This can numerous their feeling of powerlessness. Absence of help during the lamenting cycle and deficient assistance in acclimating to a domain without their folks may lead 
kids to become discouraged which leaves a solid, negative impacts on the wellbeing and improvement of the person. ${ }^{3}$

Orphans receiving orphanage/foster care report more depressive symptoms and have a higher prevalence of clinically significant depressive symptoms than children reared at home. ${ }^{4}$ Halfway houses like orphanages are liable for the training and care of the youngsters that live in them, and regularly become related with a low norm of care. A significant part of the time, they are obliged with an absence of emotional wellness and backing administrations, helpless food, and inadequate financing. Approximately 250,000 children are adopted annually, but 14,505,000 children develop up as orphans and age out of the system by age of 16 and of this number $60 \%$ of the girls become prostitutes and $70 \%$ of the boys become involved in criminal acts. The consequences of child abuse are vast, particularly when such abuse is prolonged and repeated including acute and severe outcomes such as death, injury, traumatic brain injury, as well as long-term developmental outcomes such as substance abuse, risky sexual behaviors, depression, and youth violence. These brutality and encounters are regularly neglected as they are parentless and none to gripe. ${ }^{5}$ Child abuse is a serious issue with long-lasting effects. The National Data Archive on Child Abuse and Neglect estimated that, 772,000 children were victims of abuse and neglect, worldwide; furthermost of them are living in developing countries. ${ }^{6}$ Entities who have adverse childhood experiences can be more vulnerable to disease development through both differences in physiological development and adoption and persistence of health-damaging behaviors. The orphans in orphanage institutions take more risks, have more threats, and have poorer peer influences. Male-controlled values and power structures that result in different socialization headways of the children lead them to adopting different coping mechanisms and manifesting the impression of abuse and trauma in different ways on them. They are likely to experience low self-esteem and poor psychosocial care and support. So, the children are rising up, experiencing unsafe and in secure living condition and stereotyping their sociocultural practices. ${ }^{7}$ In any case, intercessions zeroing in on both improving consideration quality and forestalling abuse are scant in our nation. Each child is honorable of having a free from any danger youth that is regardless of their economic wellbeing. Regardless of being such a colossal number that is scaling up each day, not many studies were endeavored on orphans to see the continuous unfriendly encounters that may jeopardize their physical, mental, and social development and regularly drives them towards a hazardous future life. The investigation was endeavored to decide different antagonistic encounters of orphans who reside in various orphanages in Bangladesh as it has long-standing psycho-social effect on their adulthood which frequently stays unnoticed.

\section{MATERIALS AND METHODS}

This cross-sectional study was conducted in Kodom Mubarak orphanage, Baytush Sharaf Muslim orphanage at Chittagong, and Sir Salimullah orphanage, Dhaka from 1st January to 31 st December 2017. Interviewed orphans were between 10-18 years old from the above-mentioned orphanages who were resident over there for at least three years. The sample size was calculated 384 and convenient sampling technique was applied but due to unavailability 301 participants were included in this study. A pre-tested semi-structured questionnaire was used to collect data for this research. The questionnaire was prepared based on the Life Events Checklist for DSM-5 (LEC-5) and Survey questions of 'Child violence experiences in institutionalized/orphanage care' study. Data were collected through face-to-face interviews with the orphans. Permission was taken from the orphanage authority informing them of the purpose, objective and utilization of results, and ensuring of the privacy of the respondents. Informed written consent was obtained from the respondent orphans ensuring them of their privacy before data collection. The interview was conducted by visiting their classrooms and hostels. Privacy was maintained as much as possible during the collection of data. Data were collected according to the working schedule. Descriptive statistics included distribution, percentage, mean, range, standard deviation, etc. For inferential statistics, non-parametric Chi-Square test was performed to determine the association between different variables. A p-value of $<0.05$ was considered statistically significant. The analysis plan was developed following the objectives of the study. In this study, an ethical clearance certificate was taken from the Ethical Review Board (ERB) of the National Institute of Preventive and Social Medicine (NIPSOM).

\section{RESULTS}

Table I Shows the out of 301 participants, male (84\%) outnumbered the female (16\%) participants. Among them, majority were (44.9\%) aged between 10-12 years followed by $37.9 \%$ aged between $13-15$ years of age. About $62 \%$ of participants were educated up to primary/ equivalent level and $25 \%$ had up to secondary/ equivalent level of education. Maximum (82.06\%) participants had lost any of their parents and the rest lost both of their parents 
Table I: Socio-demographic characteristics of the orphans $(\mathrm{N}=301)$

\begin{tabular}{|l|l|c|c|}
\hline Attributes & Category & Frequency (n) & Percentage (\%) \\
\hline \multirow{2}{*}{ Sex } & Male & 254 & 84 \\
\cline { 2 - 4 } & Female & 47 & 16 \\
\hline \multirow{3}{*}{ Age (in groups) } & $10-12$ & 135 & 44.9 \\
\cline { 2 - 4 } & $13-15$ & 114 & 37.9 \\
\cline { 2 - 4 } & $16-18$ & 52 & 17.3 \\
\hline \multirow{3}{*}{ Level of education } & Primary /Equivalent & 188 & 62 \\
\cline { 2 - 4 } & S.S.C./Equivalent & 38 & 13 \\
\cline { 2 - 4 } & Secondary/Equivalent & 75 & 25 \\
\hline \multirow{3}{*}{ Nature of orphan } & Single orphan & 247 & 82.06 \\
\cline { 2 - 4 } & Double orphan & 37 & 12.29 \\
\hline
\end{tabular}

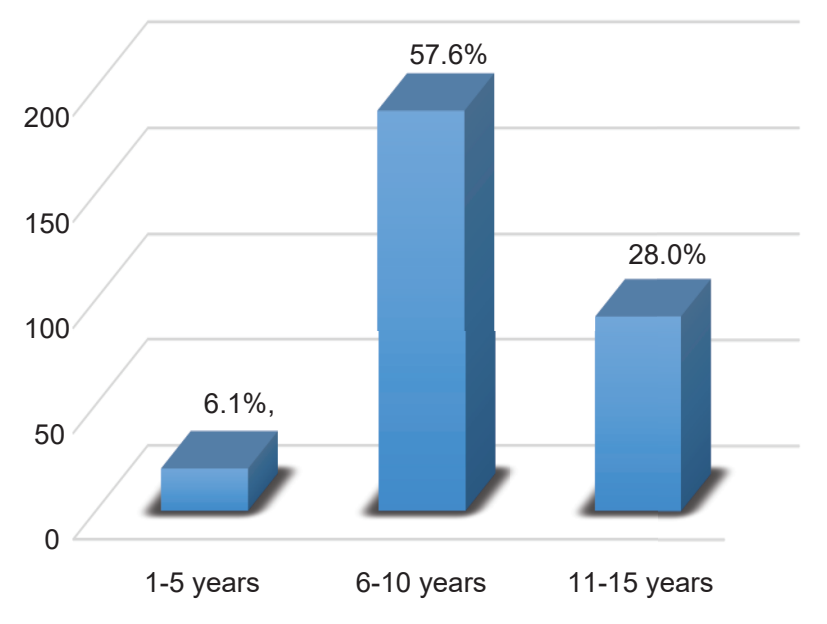

Figure 1: Duration of staying in orphanages $(\mathrm{N}=301)$

Figure 1 Shows the about 189 (57.6\%) orphans were staying in orphanage for 6-10 years, $92(28 \%)$ orphans were staying for $11-15$ years and rest $20(6.1 \%)$ were there for 1-5 years. Maximum duration of staying in orphanage was 15 years and minimum duration 5 years . Mean $( \pm$ SD) duration was $7.98 \pm 2.31$ years

Table II Shows the according to the table, about $8.2 \%$ of participants said terrific transportation accidents happened with themselves but a maximum (47.3\%) of them saw this event happening to someone. About $36.8 \%$ participants saw serious domestic accident happening to someone followed by $27 \%$ of them said the event happened with their own. Experience of physical assault was the highest (30.2\%) among them who responded this event happened with their own and $28.3 \%$ said they saw this event happening to someone. About $26.9 \%$ participants experienced exposure to toxic substances by hearing from someone and $6.2 \%$ of them were exposed personally. Of the participants, about $23 \%$ of them encountered attack with a weapon by observing it happening followed by $30.3 \%$ heard of this event happening to someone. Result shows, $4.6 \%$ participants experienced sexual assault personally and maximum (26.1\%) heard of this event happened to someone. Life-threatening illness/injury happened personally with $33.6 \%$ of participants. Almost $22.2 \%$ of participants said they experienced the event of sudden violent deaths by observing it happening to somebody and $34.4 \%$ of them heard of this event. Experience of domestic accidents by oneself was highest among the 16-18 age group and 39.2\% of participants of 10-12 years of age saw that event happening to someone which was found statistically significant $(\chi 2=32.673, \mathrm{p}<$ $0.05)$ 
Table II: Distribution of participants according to the nature of experiencing events (multiple responses)

\begin{tabular}{|c|c|c|c|}
\hline Attributes & Category & Frequency $(\mathbf{n})$ & Percentage (\%) \\
\hline \multirow{4}{*}{$\begin{array}{l}\text { Experience of terrific } \\
\text { transportation accident } \\
(\mathrm{n}=317)\end{array}$} & Happened with oneself & 26 & 8.2 \\
\hline & Saw happening to someone & 150 & 47.3 \\
\hline & Heard from someone & 88 & 27.8 \\
\hline & Didn't experience & 53 & 16.7 \\
\hline \multirow{4}{*}{$\begin{array}{l}\text { Experience of serious } \\
\text { domestic accident } \\
(\mathrm{n}=318)\end{array}$} & Happened with oneself & 86 & 27.0 \\
\hline & Saw happening to someone & 117 & 36.8 \\
\hline & Heard from someone & 73 & 23.0 \\
\hline & Didn't experience & 42 & 13.2 \\
\hline \multirow{4}{*}{$\begin{array}{l}\text { Experience of physical } \\
\text { Assault }(\mathrm{n}=318)\end{array}$} & Happened with oneself & 96 & 30.2 \\
\hline & Saw happening to someone & 90 & 28.3 \\
\hline & Heard from someone & 72 & 22.6 \\
\hline & Didn't experience & 60 & 18.9 \\
\hline \multirow{4}{*}{$\begin{array}{l}\text { Experience of exposure to } \\
\text { toxic substances }(n=305)\end{array}$} & Happened with oneself & 19 & 6.2 \\
\hline & Saw happening to someone & 72 & 23.6 \\
\hline & Heard from someone & 82 & 26.9 \\
\hline & Didn't experience & 132 & 43.3 \\
\hline \multirow{4}{*}{$\begin{array}{l}\text { Experience of assault } \\
\text { with a weapon }(n=304)\end{array}$} & Happened with oneself & 9 & 3.0 \\
\hline & Saw happening to someone & 70 & 23.0 \\
\hline & Heard from someone & 92 & 30.3 \\
\hline & Didn't experience & 133 & 43.8 \\
\hline \multirow{4}{*}{$\begin{array}{l}\text { Experience of sexual } \\
\text { assault }(n=303)\end{array}$} & Happened with oneself & 14 & 4.6 \\
\hline & Saw happening to someone & 54 & 17.8 \\
\hline & Heard from someone & 79 & 26.1 \\
\hline & Didn't experience & 26 & 51.5 \\
\hline \multirow{4}{*}{$\begin{array}{l}\text { Experience of life } \\
\text { threatening illness/injury } \\
(\mathrm{n}=307)\end{array}$} & Happened with oneself & 150 & 33.6 \\
\hline & Saw happening to someone & 88 & 26.7 \\
\hline & Heard from someone & 53 & 22.8 \\
\hline & Didn't experience & 86 & 16.9 \\
\hline \multirow{3}{*}{$\begin{array}{l}\text { Experience of sudden } \\
\text { violent death }(\mathrm{n}=302)\end{array}$} & Saw happening to someone & 117 & 22.2 \\
\hline & Heard from someone & 73 & 34.4 \\
\hline & Didn't experience & 42 & 43.4 \\
\hline
\end{tabular}

Table III. Shows the study also revealed, the experience of exposure to toxic chemicals by both personally and seeing it transpiring was the highest among $10-12$ years of age members $(\chi 2=18.650, \mathrm{p}<0.05)$. It was evident from the study that, the experience of sexual assault personally was the highest among 13-15 years age group followed by 10-12 years aged participants. The variety of this event by age was found significant statistically $\left(\chi^{2}=14.637, \mathrm{p}<0.05\right)$. Experience of domestic accidents personally was highest among 16-18 years old orphans compared to other groups $(\chi$ $2=32.673, \mathrm{p}<0.05)$. Experience of physical assault personally was highest within the same age group though this relation wasn't statistically significant. Furthermore, orphans aged from 10-12 years experienced sexual assault $(\chi 2=14.637, \mathrm{p}<0.05)$ and physical assault through seeing it transpiring than other age groups that were evident from the study 
Table III: Age of the participants and nature of experiencing events $(\mathrm{N}=301)$

\begin{tabular}{|c|c|c|c|c|c|c|}
\hline Age group & $\begin{array}{c}\text { Happened } \\
\text { with oneself } \\
\mathbf{f}(\%)\end{array}$ & $\begin{array}{c}\text { Saw } \\
\text { happening } \\
\mathbf{f}(\%)\end{array}$ & $\begin{array}{c}\text { Heard from } \\
\text { someone } \\
\mathbf{f}(\%)\end{array}$ & $\begin{array}{c}\text { Didn`t } \\
\text { experience } \\
\mathbf{f}(\%)\end{array}$ & $\begin{array}{l}\text { Total } \\
\mathbf{f}(\%)\end{array}$ & Significance \\
\hline \multicolumn{7}{|c|}{ Transportation accident } \\
\hline $10-12$ & $12(9.2)$ & $7154.6)$ & $30(23.1)$ & $17(13.1)$ & $130(100.0)$ & $\chi^{2}=5.729$ \\
\hline $13-15$ & $10(8.0)$ & $54(43.2)$ & $35(28.0)$ & $26(20.8)$ & $125(100.0)$ & $\mathrm{df}=6$ \\
\hline $16-18$ & $4(8.7)$ & $19(41.3)$ & $13(28.3)$ & $10(21.7)$ & $46(100.0)$ & $\mathrm{p}=.454$ \\
\hline \multicolumn{7}{|c|}{ Domestic accident } \\
\hline $10-12$ & $29(22.3)$ & $51(39.2)$ & $41(31.5)$ & $9(6.9)$ & $130(100.0)$ & $\chi^{2}=32.673$ \\
\hline $13-15$ & $34(27.2)$ & $41(32.8)$ & $23(18.4)$ & 27 (21.6) & $125(100.0)$ & $\mathrm{df}=6$ \\
\hline $16-18$ & $23(50.0)$ & $15(32.6)$ & $2(4.3)$ & $6(13.0)$ & $46(100.0)$ & $\mathrm{p}=.000$ \\
\hline \multicolumn{7}{|c|}{ Physical assault } \\
\hline $10-12$ & $36(27.7)$ & $40(30.8)$ & $31(23.8)$ & $23(17.7)$ & $130(100.0)$ & $\chi^{2}=5.628$ \\
\hline $13-15$ & $42(33.6)$ & $30(24.0)$ & $23(18.4)$ & $30(24.0)$ & $125(100.0)$ & $\mathrm{df}=6$ \\
\hline $16-18$ & $18(39.1)$ & $11(23.9)$ & $10(21.7)$ & $7(15.2)$ & $46(100.0)$ & $\mathrm{p}=.466$ \\
\hline \multicolumn{7}{|c|}{ Exposure to toxic chemicals } \\
\hline $10-12$ & $13(10.0)$ & $40(30.8)$ & $33(25.4)$ & $44(33.8)$ & $130(100.0)$ & $\chi^{2}=18.650$ \\
\hline $13-15$ & $6(4.8)$ & $25(20.0)$ & $35(28.0)$ & $59(47.2)$ & $125(100.0)$ & $\mathrm{df}=6$ \\
\hline $16-18$ & $0(0.0)$ & $7(15.2)$ & $10(21.7)$ & $29(63.0)$ & $46(100.0)$ & $\mathrm{p}=.005$ \\
\hline \multicolumn{7}{|c|}{ Assault with a weapon } \\
\hline $10-12$ & $3(2.3)$ & $29(22.3)$ & $45(34.6)$ & $53(40.8)$ & $130(100.0)$ & $\chi^{2}=6.109$ \\
\hline $13-15$ & $5(4.0)$ & $29(23.2)$ & $37(29.6)$ & $54(43.2)$ & $125(100.0)$ & $\mathrm{df}=6$ \\
\hline $16-18$ & $1(2.2)$ & $11(23.9)$ & $8(17.4)$ & $26(56.5)$ & $46(100.0)$ & $\mathrm{p}=.411$ \\
\hline \multicolumn{7}{|c|}{ Sexual assault } \\
\hline $10-12$ & $7(5.4)$ & $32(24.6)$ & $30(23.1)$ & $61(46.9)$ & $130(100.0)$ & $\chi^{2}=14.637$ \\
\hline $13-15$ & $7(5.6)$ & $19(15.2)$ & $35(28.0)$ & $64(51.2)$ & $125(100.0)$ & $\mathrm{df}=6$ \\
\hline $16-18$ & $0(0.0)$ & $2(4.3)$ & $13(28.3)$ & $31(67.4)$ & $46(100.0)$ & $\mathrm{p}=.023$ \\
\hline \multicolumn{7}{|c|}{ Life threatening injury/illness } \\
\hline $10-12$ & $42(32.3)$ & $34(26.2)$ & $35(26.9)$ & 19 (14.6) & $130(100.0)$ & $\chi^{2}=5.433$ \\
\hline $13-15$ & $41(32.8)$ & $32(25.6)$ & 27 (21.6) & $25(20.0)$ & $125(100.0)$ & $\mathrm{df}=6$ \\
\hline $16-18$ & $20(43.5)$ & $12(26.1)$ & $6(13.0)$ & $8(17.4)$ & $46(100.0)$ & $\mathrm{p}=.490$ \\
\hline
\end{tabular}

\section{DISCUSSION}

This study which was conducted to assess the adverse childhood experiences among orphans who reside in different orphanages. It was a cross sectional study where 301 orphans participated from different orphanages in Chittagong and Dhaka city. According to this study, majority of them (44.9\%) were between $10-12$ years, 37.9 $\%$ were between $13-15$ years and on the other hand $17.3 \%$ orphans were aged between 16-18 years which was the minority group. In this study, male were $84 \%$ and female $16 \%$. This study was done among the orphans who's age were in the range of 10-18 years. Mean $( \pm$ SD) age of this orphans were $13.31 \pm 1.696$ years. Study by Hermenau et al., (2015) conducted a study on maltreatment in institution rearing children among 14 female orphans with mean \pm SD was $9.79 \pm 1.45$ years. ${ }^{8}$ Gray et al., (2015) conducted a study on traumatic experiences among orphans in institutional and family-Based settings orphans 
where 1063 was his sample size among whom $51.83 \%$ were female and almost $48.16 \%$ male which was aimed to assess violence experiences among institutional cared orphans aged between 10-12 years.9 Gray et al.,(2015) conducted their study between 6-12 years age range of orphans. ${ }^{9}$ According to a study of Tadesse et al.,(2014) in Ethiopia on psychosocial wellbeing of orphan in orphanages where age range of the participant orphans was 10-17 years which almost coincides with this study. ${ }^{10}$ However, variation in study findings may be due to variation of places, duration of study period. Only female orphanages are not easy to access and less available. Moreover, we can hardly get male and female orphans together in a very few orphanage in our country's perspective. Maybe it is a reason of this disproportionate ratio of male and female orphans in this study. Maximum age limit was 18 as up to this year orphans are considered as so and after this age they are not allowed to stay in orphanages in our country.

In this study, among this 301 orphans, majority of this orphans lost one their parents (82\%) than both of them (18\%) where $210(64 \%)$ orphans lost only their father/ paternal orphan, 37 (11.3\%) lost their mother/maternal orphan and about $54(16.5 \%)$ lost both of them. Orphans who loses both of their parents are forced by their fate to earn their livelihood rather than getting shelter in orphanages as they have none to take them in orphanages. Moreover, after losing their father, it becomes difficult for their mother to bear his/her expenses as father earns mostly in a family in our country`s perspective. Maybe it is a reason for what there are more single and paternal orphans in this study. This study included the data of the orphans of duration of their staying in orphanage. Here $20(6.1 \%)$ of them were staying for $1-5$ years, $189(57.6 \%)$ for 6-10 years and 92(28.0\%) orphans were staying for 11-15 years. Maximum duration was 15 years and minimum 5 years where mean $( \pm S D)$ was $7.98( \pm 2.231)$ years. Tadesse et al., (2014) on orphans where study population should had at least 1 year experience of staying in orphanage. ${ }^{10}$

The study showed, experience of physical assault was the highest (30.2\%) among them who responded this event happened with their own and $28.3 \%$ said they saw this event happening to someone and this experience wasn't associated with age. Again, $4.6 \%$ participants experienced sexual assault personally and maximum $(26.1 \%)$ heard of this event happened to someone. The experience of sexual assault personally was the highest among 13-15 years age group followed by 10-12 years aged participants which was significant statistically. A similar study conducted by Gray et al., (2015) found 50.3\% of 1053 children in institutional care across 5 countries experienced physical or sexual abuse with no differences by gender, but more abuse among the younger age groups. ${ }^{9}$ Cristine et al., (2015) conducted a longitudinal study where by using Life Event Checklist assessed different adverse experiences. They found more than half of children in institutions $50.3 \%$ $[95 \% \mathrm{CI}=42.5,58.0])$ and in family-based care $(54.0 \%$ $[95 \% \mathrm{CI}=50.2,57.7])$ had experienced physical or sexual abuse by age 13 out of 1,357 institution-dwelling and 1,480 family-dwelling orphaned and separated children. ${ }^{11}$

In this study, orphans said they experienced threatening or injury by weapon, among whom $3 \%$ of them experienced through happening with themselves, $23 \%$ by seeing while occurred with others and $30.3 \%$ learned from someone about this event and in case of $43.8 \%$ orphans this event didn't happen. Maximum orphans (43.8 \%) didn't experienced this event and minimum (6\%) orphans experienced it personally. Experience of assault with a weapon one way or another didn't have statistical significance. Possible explanation can be as they reside at orphanage and little chance of involvement in political, criminal activities as well as victimization of terrorism where firearms, knife, gun are usually used. Almost 22.2\% of orphans saw someone to suicide or homicide but $34.4 \%$ of orphans had learnt about that from someone close to $\mathrm{him} /$ her and $43.4 \%$ of them didn't experience this event. It is very likely that they share stories of experiencing of suicide or homicide that they witnessed or learnt from someone like neighbors or people around them. Maybe this a cause for what $34.4 \%$ orphans said they learnt of this event from someone else rather than seeing it by own self.

\section{CONCLUSIONS}

Experience of life-threatening illness/injury that required hospitalization was the most frequent event revealed by this study. The experience of physical abuse had the second-highest frequency and was pretty much incessant in all age groups.

\section{LIMITATIONS}

1. This study was confined to metropolitan orphanages of two urban areas because of time limitations. So the result probably won't be generalized.

2. Male and female participants were disproportionate due to the difficulty of access to the female orphanages.

\section{RECOMMENDADTION}

Further studies are required in bigger degree to survey their actual need with the goal that specific strategies can be embraced explicitly to defeat the deterrent for guaranteeing their privileges and benefit. 


\section{REFERENCES}

1. UNICEF for every child: Orphans. accessed at: https://www.unicef.org/media/orphans [Cited on 2019 June 26]

2. Radenkovic M. 11-countries-with-highest-orphan-population. [Internet]. New Jersey, USA: January 11, 2016. Available from: https://www.insidermonkey. com/blog/ -

3. Allen E, Orme T, McCarter R, Grossman L. Self-reported depressive symptoms in school-age children at the time of entry into foster care. Ambulatory Child Health. 2000; 6(1):45-57

4. Shiferaw G, Bacha L, Tsegaye D. Prevalence of Depression and Its Associated Factors among Orphan Children in Orphanages in Ilu Abba Bor Zone, South West Ethiopia. Psychiatry Journal. 2018 October $15 . \quad$ Available from: https://doi.org/10.1155/2018/6865085

5. Kumsta R, Kreppner J, Rutter M, Beckett C, Castle J, Stevens S, Sonuga-Barke EJS. Deprivation-specific psychological patterns. Monographs of the Society for Research in Child Development. 2010; 75: 48-78. Available from: http://dx.doi.org/10.1111/j. 1540-5834.2010.00550.x

6. National Data Archive on Child Abuse and Neglect (NDACAN), (Ed.), National child abuse and neglect data system (NCANDS) child file, FFY 2011, NDACAN dataset number 169, user's guide and codebook (Brofenbrenner Center for Translation Research ed.). Ithaca, NY: Cornell University.2011
Available from: https://pdfs.semanticscholar. org/ c606/099735c52b048d95a3c9e0f029d9d22496a5.p $\mathrm{df}$

7. Glenn D.WolfnerRichard J.Gelles. A profile of violence toward children: A national study. Child Abuse \& Neglect. 1993 Mar-Apr;17(2):197-212

8. Hermenau K, Kaltenbach E, Mkinga G, Hecker, T. Improving care quality and preventing maltreatment in institutional care - A feasibility study with caregivers. Frontiers in Psychology. 2015; 6:1-7. doi:10.3389/fpsyg.2015.00937.

9. Gray CL, Pence BW, Ostermann J, Whetten RA, O'Donnell K, Thielman NM, et al. Prevalence and incidence of traumatic experiences among orphans in institutional and family-based settings in 5 low- and middle-income countries: a longitudinal study. Glob Health Sci Pract. 2015; 3(3):395-404.

10. Tadesse S, Dereje F, Belay M. Psychological wellbeing of orphan and vulnerable children at orphanages in Gondar Town, North West Ethiopia. Journal of Public Health and Epidemiology. 2014; 6:293-301.

11. Christine L Gray, Brian W Pence, Jan Ostermann, Rachel A Whetten, Karen O'Donnell, Nathan M Thielman, Kathryn Whetten. Prevalence and Incidence of Traumatic Experiences among Orphans in Institutional and Family-Based Settings in 5 Lowand Middle-Income Countries: A Longitudinal Study. Global Health: Science and Practice. Sep 2015; 3 (3) 395-404; DOI: 10.9745/GHSPD-15-00093 